\section{CELL-FREE SECRETION}

Stephen W. Carmichael ${ }^{1}$, Mayo Clinic

Regulated secretion occurs when the cell detects a signal, vesicles containing the secretory product fuse with the plasma membrane of the cell, and the contents are released into the extracellular space. This mechanism is called exocytosis. Many laboratories around the world have studied exocytosis for the past couple of decades, and we know a lot about the many steps that are involved. The cytoskeleton appears to play a role in allowing vesicles to approach the plasma membrane, and many other proteins are in the cascade between reception of the signal and the release of the secretory products. But which steps are essential, which ones are regulatory, and which ones modulate secretion? In order to answer these questions, we need a simple model system; intact cells are simply too complicated. While many models have been utilized to unravel the mechanisms of exocytosis, a cell-free system is needed. This "Holy Grail" of secretion has been sought, and it looks like we now have one.

This breakthrough was recently reported by Julia Avery, Darren Ellis, Thorsten Lang, Phillip Holroyd, Dietmar Riedel, Robert Henderson, Michael Edwardson, and Reinhard Jahn. After several preliminary studies, they took advantage of the fact that a fluorescent marker called acridine orange is a weak base. Acridine orange is sequestered within vesicles that have an acidic interior. The cell they began with is called the PC12 cell, derived from a tumor of the rat adrenal medulla. PC12 cells are a type of chromaffin cell that grows particularly well in culture, and chromaffin cells are notable for containing vesicles that are acidic ( $\mathrm{pH}$ about 5.5). As acridine orange becomes concentrated within these vesicles, they form dimers and larger aggregates, and due to a phenomenon called quenching, these aggregates do not fluoresce. During exocytosis, when the vesicle contents are released into the extracellular medium, the acridine orange is diluted and fluoresces. This is the basis of the assay that Avery et al. used in their study.

PC12 cells were loaded with acridine orange, then they were physically disrupted with ultrasonic waves. After just the right amount of physical disruption, Avery et al., could visualize patches of plasma membrane with secretory vesicles attached. Using cytochemical markers for mitochondria and other organelles, they determined that virtually nothing else remained, therefore they had a cell-free system. With a phase contrast microscope, they could visualize patches of membrane. With a fluorescence microscope, they could see flashes of fluorescence when the appropriate amount of calcium was added to the incubation medium. It is known that, under most circumstances, calcium ions are required for exocytosis to occur. When calcium was eliminated from the medium (by a chelating agent) the fluorescent flashes ceased. The flashes were interpreted to represent the release of acridine orange into the incubation medium. If this is the correct interpretation, then we have a cell-free assay for exocytosis.

Several different types of microscopes were used to strengthen the evidence for this cell-free system. Transmission electron microscopy demonstrated chromaffin vesicles attached to pieces of membrane in unstimulated specimens. In specimens treated with calcium, the number of chromaffin vesicles was significantly decreased. The atomic force microscope (AFM) was used to image fixed specimens, both stimulated and unstimulated, with the number of attached particles being dramatically reduced in the stimulated specimens. Finally, the AFM was used to capture "live" images from unfixed specimens in an aqueous environment. When calcium was added to the medium, scans about 4 minutes apart showed a dramatic decrease in the number of vesicles on the patches. This demonstrates the potential for temporal resolution, as well as spatial resolution, of exocytosis.

As another control, Avery et al., also showed that tetanus toxin, which is known to block exocytosis, also blocked secretion in their cell-free system. And interestingly, an extract of cytosol had to be included in the incubation medium for exocytosis to occur. However, we finally have a system where the process of exocytosis can be methodically dissected. Using this system, we should be able to separate steps that are essential, from those that regulate and modulate secretion. An exciting development, indeed!

1. The author gratefully acknowledges Dr. Reinhard Jahn for reviewing this article.

2. Avery, J., D.J. Ellis, T. Lang, P. Holroyd, D. Riedel, R.M. Henderson, J.M. Edwardson, and R. Jahn, A cell-free system for regulated exocytosis in PC12 cells, Journal of Cell Biology, 148:317-324, 2000.

3. For more information about chromaffin cells, check out the web site: www.chromaffincells.org

\title{
INDEX OF ARTICLES
}

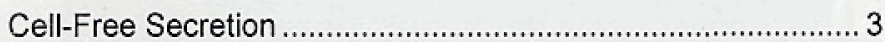
Stephen W. Carmichael, The Mayo Clinic

Microscopy Horror Stories

The Unusual Degradation of Recordable Compact Discs...... 24 James Martin, Orion Analytical

3D Reconstruction of Thick IVEM Samples Using Aperture... 26 Computed Tomography® (TACT®)

W. Grey Jerome, Ken Grant, Patricia G. Yancey, A.M. Al Gailany, Wolfram Betterman, Richard L. Webber, Wake Forest University School of Medicine
Sources and Remedies of Phototoxicity in Live Cell...............30 Microscopy Philip Hockberger, Northwestern University

An Improved Clamp for Gluing TEM Cross Section Samples. 33 Hao Li and L. Salamanca-Riba, University of Maryland

Comment on Formalin Safety ......................................... 34 Dick Dapson, Anatech Ltd.

Anomalous Changes in Tip Height in Tapping AFM. .36 Jason Cleveland, Asylum Research 


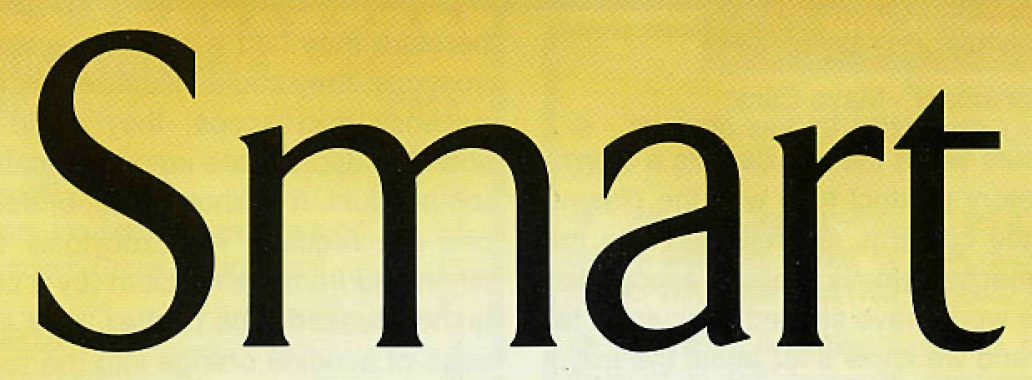

\section{Introducing the \\ Personal SEM 2000 ... revolution- izing microscopy and microanalysis for tomorrow}

The Personal SEM 2000 will be the preferred way for microscopy and microanalysis today and tomorrow. Just as the Personal Computer revolutionized the computer industry, the Personal SEM 2000 is revolutionizing the microscopy and microanalysis industry. There's a strong analogy. Versatility to be tailored exactly to specific industries, but yet affordable; power to do virtually all the tasks you want; and highly sophisticated, but easy to use. Just as the Personal Computer has become a critical element in business, so will the Personal SEM 2000.

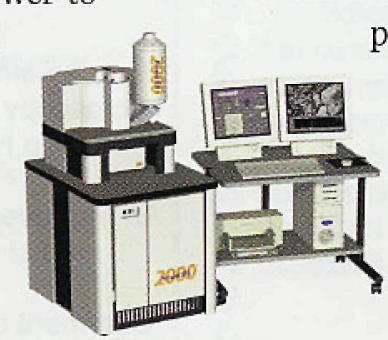
you look smart. Maximum versatility and
power but simple to use. The digital imaging you look smart. Maximum versatility and
power but simple to use. The digital imaging is unsurpassed.

Whether you're a seasoned professional or just starting out, the Personal SEM 2000 will make The only integral SEM/EDX. No integrating problems. No discrepancies. And yes, no servicing hassles. Why? You have a single source supplier and guarantee - R J Lee Instruments.

The Personal SEM 2000 ... a strong, versatile, expandable workhorse SEM ...you won't outgrow its capability. Take a closer look and see how this smart product makes you look smart. Call 1-800-538-6850 or visit our website www.rileeinst.com. 
$\star$ With the Microscopy and Microanalysis 2000 Meeting Search Engine, one can now find papers (subjects and/or authors), times, locations, session, etc. Just go to:

www.msa.microscopy

And follow the links to the M\&M 2000 Meeting.

\section{$\star \quad$ M\&M 2000 Exhibitor Demonstrations}

Once again, MSA's Education Committee is organizing mini-seminar or tutorial demonstrations known as "Exhibitor Demonstrations". These sessions are conducted by Exhibitors right in their own booth(s). Exhibitor demonstrations are the perfect way to make attendees more knowledgeable about products and services, at no charge, to the attendees. Admission is limited and controlled by tickets issued at the Education Committee Booth on the exhibit floor.

Participating exhibitors will be listed on a sign at the entrance to the exhibit hall on Monday and Tuesday. There will also be individual signs provided for the booths identifying them as participating exhibitors. If you are interested in offering an Exhibitor Demonstration, please contact Tina Carvalho of MSA's Education Committee:

Tina Carvalho

University of Hawaii

Biological EM Facility

Tel.: (808)956-6251

Fax: (808)956-5043

eMail (recommended): tina@pbrc.hawaii.edu

\section{$\star$ Microscopy \& Microanalysis 2000 Annual Golf Tour- nament}

The winter weather has broken and golfers once again fill the courses in the Northeast. Your M\&M 2000 crew have selected a truly outstanding course for this year's traditional scramble event. Don't miss this opportunity for a memorable round with your colleagues and friends.

The thirteenth annual golf tournament will be played the morning of August 13th at the Wyncote Golf Club in pastoral Oxford, PA. This seven-year old course annually competes for Best-Of-Pennsylvania status and regularly hosts regional golf association tournaments. Built as a true links, Wyncote features shared greens, sweeping vistas, rolling terrain, thick gorse, a reputation for excellent maintenance and service but nary a tree. The cost is $\$ 80$ per person including greens fees, cart, box lunch and transpiration with buses leaving the convention center at 7:30 AM.

Reserve your space today using the Microscopy and Microanalysis 2000 registration form, on-line at www.msa. microscopy.com or by calling meeting management at ( 877 ) 672-6271.

\section{* Late Breaking Poster Session at M\&M 2000}

Microscopy \& Microanalysis 2000 will feature a poster session composed at presentations of newly acquired data or analyses which were unavailable for submission by the February 15 deadline. A short, half page abstract describing the studies is required. The abstract should include: Title, Authors, Authors affiliation, and a Brief Description of the studies. The description should include the aim of the studies, a short characterization of the methods, and a brief account of the results and their importance.
Abstracts should be emailed (stuartm@tc.umn.edu) or faxed (612-625-5368) to the program chair, Stuart McKernan. Abstracts may be submitted immediately but must be received by June 23,2000 . Abstracts will be reviewed by members of the program committee. A limited number of poster boards are available and preference will be given to early submissions. Abstract authors will be notified of acceptance of their abstracts no later than July 1 (earlier for early submissions)

\section{$\star$ Just For Fun Micrograph Contest}

Due to the response (and fun) of having our contest last year, we will repeat the contest at M\&M 2000.

The concept of the contest is based composite images, made up of two or more images, at least one of which must be microscopical in nature. Contestants may enter up to two images and do not have to be present to win.

Entries will be displayed in our booth and conference attendees will be invited to vote on which they consider the most "creative and interesting". First prize will be $\$ 300$, with $\$ 200$ and $\$ 100$ for second and third prizes, respectively. Winning entrees, and perhaps others, will be featured as cover images on this publication. All contestants will receive their choice of two microscopy prints by David Scharf.

Entries must, of course, be in hard copy. They may be either in black and white or full color. While any reasonable size is acceptable, a size of $81 / 2 \times 11$ inches is recommended. Entries should be mounted on a rather stiff backing material. A $3^{\prime \prime}$ $x 5^{\prime \prime}$ card should accompany each entry-with image description and contributors name and affiliation.

Entries are welcome from all interested in microscopy, certain to include those overseas as well as manufacturers and suppliers.

Those with a potential interest in participating in the contest should advise by fax (608-836-1969) or email (microtoday@mindspring.com). We, in turn, will insure that they receive any further information on the contest.

Entries may be sent to Microscopy Today in advance of the conference or may be delivered to our booth at the conference.

Please do advise if you intend to supply one or two images just to be sure that we have adequate display space.

I hope that you will consider participating. ... Don Grimes, Editor

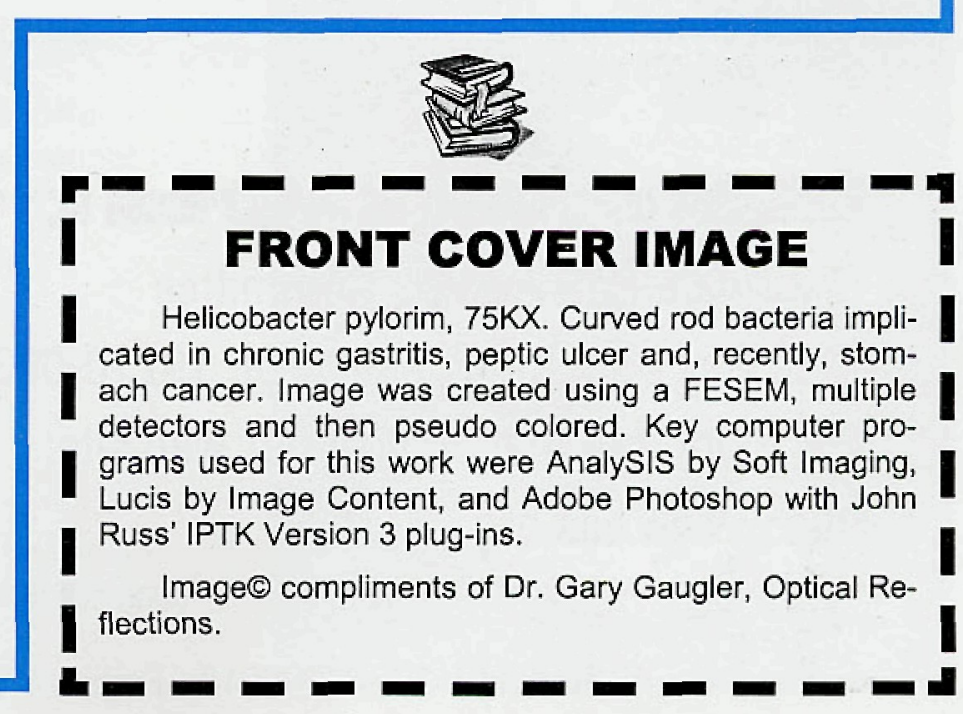




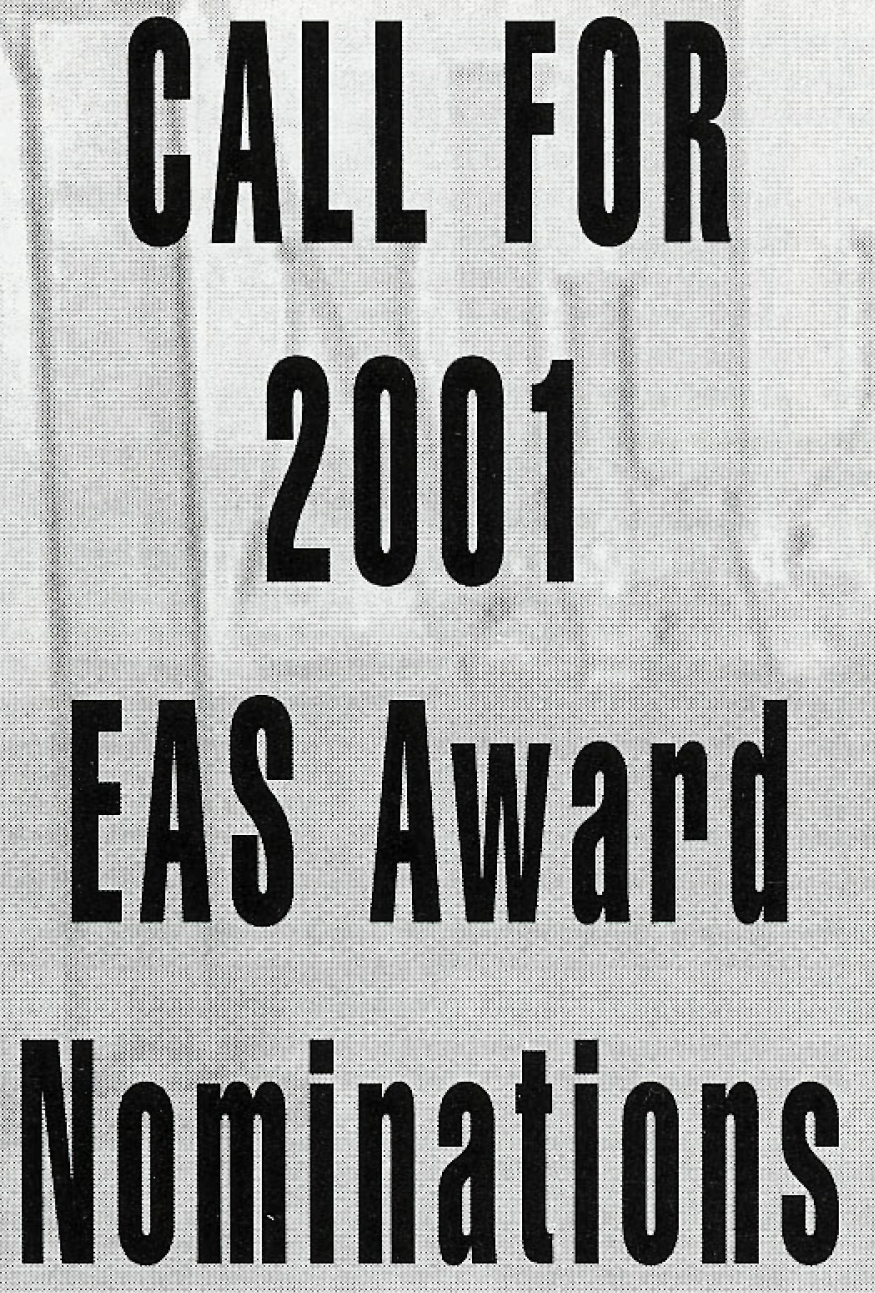

EAS is soliciting nominees for its 2001 Awards for Outstanding

Achievement in:

- Fields of Analytical Chemistry

- Near-Infrared Spectroscopy

- Separation Science

- Magnetic Resonance

- Chemometrics

The deadline for receipt

of nominations is

June 30, 2000.

These awards will be

presented at the 2001

Eastern Analytical Symposium, to be

held in Atlantic City, New Jersey.

A primary letter of recommendation should be submitted by someone familiar with the nominee's work and should be no more than six pages in length. It should include a discussion of his or her work's significance, a list of publications, presentations, and awards, and a statement of the nominee's willingness to present their work at an EAS Award Symposium. Each Award consists of an honorarium, plaque, travel expenses and the opportunity for the awardee to present his or her work to the attendees at an Award Symposium.

Nomination materials should be addressed to:

Chairman, EAS Awards Committee

P. 0. Box 633, Montchanin, DE 19710-0633 USA

For more information visit our web site:

http://www.eas.org

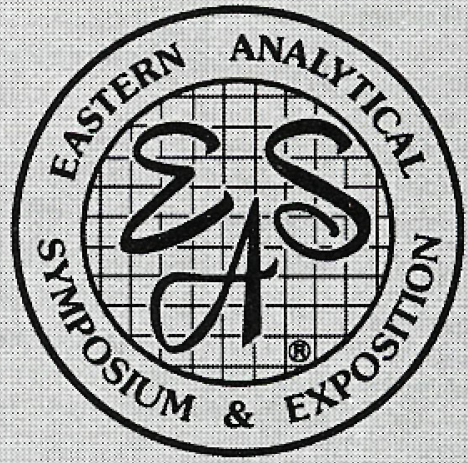




\section{ooming arentis}

May 23/25 '00: Fundamentals of Asbestos Analysis by Transmission Electron Microscopy

$\checkmark$ May 22/June 2 '00: PASEM 2000 (Univ. of Maryland) College Park, Md., Tim Maugel: (301)405-6898, tm11@umail.umd.edu

$\checkmark$ June 5/16 '00: XRF2000-A Short Course in Midern X-ray Spectroscopy (Univ. of Western Ontario) London, Ontario. Dr. Charles Wu: (519)661-3791

$\checkmark$ June 10/17 '00: Optical Microscopy in the Biological Sciences. (Univ. of Texas Health Science Ctr) San Antonio, TX. www.uthscsa.edu/ gsbs/csbhome.html

\section{LEHIGH MICROSCOPY SCHOOLS}

$\checkmark$ June 12/16 '00: SEM and X-ray Microanalysis

$\checkmark$ June 11 '00: Introduction to SEM and EDS

$\checkmark$ June 19/23 '00: Advanced Scanning Electron Microscopy

$\checkmark$ June 19/23 '00: Quantitative X-ray Microanalysis

$\checkmark$ June 19/22 '00: Analytical Electron Microscopy

$\checkmark$ June 20/23 '00: Atomic Force Microscopy

$\checkmark$ June 22/24 '00: Thin Specimen Preparation

$\checkmark$ June 19/23 00 : Microdiffraction

$\checkmark$ June 21/23 '00: Cryo SEM

For further information, contact Ms. Sharon Coe at Tel.: (610)758-

5133 or by eMail at sharon.coe@lehigh.edu

\section{$\checkmark$ 3D MICROSCOPY OF LIVING CELLS}

June 19/29 '00: 3D Microscopy of Living Cells

July 1/3,00: 3D Image Processing

Univ. of British Columbia, Vancouver, $\mathrm{BC}$,

www.cs,ubc.ca/spider/ladic/course/bulletin.html

$\checkmark$ June 22 '00: 16th Annaul Short Course on Molecular Microspectroscopy Miami University) Oxford, $\mathrm{OH}$. http://www.muohio. edu/ sommeraj

$\checkmark$ June $23^{\prime} 00$ : 2nd International Conference on Scanning Probe Microscopy in Biomaterials Science. Bristol, U.K., Dr. Klaus Jandt: K jandt@bris.ac.uk

$\checkmark$ June 26/30 '00: 7th Asia-Pacific Conference on Electron Microscopy Singapore. eMail: micngml@nus.edu.sg or medlab2@nus.edu.sg http://www.med.nus.edu.sg/micsoc/7apem

$\checkmark$ June 26/30 '00: Summer School on Computing in Electron Microscopy (NCEM, Lawrence Berkeley National Lab) Berkeley, CA. (510)486-6036, http://ncem.lbl.gov/frames/workshops.htm\#workshops

$\checkmark$ July 2/5 00: International Kunming Symposium on Micdroscopy, Kunming, China, http://www.iphy.ac.cn/microsc/lKSM.html

$\checkmark$ July 3/8 00 : Xith International Congress of Histochemistry and Cytochemistry. (Royal Microscopical Society), York, U.K., www.med.ic. ac.uk/external/ichc_2000/

$\checkmark$ July 9/14 '00: 2nd Meeting of the International Union of Microbeam Analysis Societies. Kailua-Kona, Hawaii. www.microanalysis. org/iumas 2000

$\checkmark$ July $9 / 14$ '00. 12th European Congress on Electron Microscopy. Bruno, Czech Republic. http://www.eurem2000.isibrno.cz/

$\checkmark$ July 17/19 '00: Electron Microprobe Analysis by Wavelength Dispersive Spectroscopy. (MIT) Cambridge, MA. E-probe-www@mit. edu, (617)253-1995.

$\checkmark$ July 27/29 '00: International Kunming Symposium on Microscopy (Chinese Electron Microscopy Society) Kunming, P.R. China. IKSM Office: IKSM@aphy.iphy.ac.cn

$\checkmark$ August 13/17 '00: Microscopy \& Microanalysis '00: (MSA) Philadelphia, PA. Annamarie Dowling / Mary Beth Rebedeau: (708)3616045, rebgroup@earthlink.net $\checkmark$ August 17/19 '00: Fundamentals of Light Microscopy August 21/23 '00: Polarized Light Microscopy Wellesley College, Wellesley, MA. Mary McCann: (617)484-7865

$\checkmark$ August 22/26 '00: Scanning Probe Microscopy of Polymers. (American Chemical Society) Washington, D.C. Vladimir V. Tsukruk: ((515) 294-6904

$\checkmark$ September 3/8 00: 11th International Congress of Histochemistry York, U.K., www.med.ic.ac.uk/external/ichc_2000

$\checkmark$ September 10/15 '00: CLEO/Europe-IQEC 2000

$\checkmark$ October 11/19 '00: Optical Microscopy \& Imaging in the Biomedical Sciences. (Marine Biological Laboratory), Woods Hole, MA. Carol Hamel: (508)289-7401, admissions@mbl.edu

$\checkmark$ October 16/20 '00: FLUORESCENCE 2000-Advanced Courses of Fluorescence Microscopy and Confocal Microscopy. Lake of Garda, Italy. Dr. Annalisa Imberti: +390270646234 , http://users.unimi.it/ fl2000/

$\checkmark$ October 17/19 '00: Fundamentals of Asbestos Analysis by Transmission Electron Microscopy (MVA, Inc.) Norcross GA: (770)6628509

$\checkmark$ November $12 / 166^{\circ} 00$ : International Symposium for Testing and Failure Analysis. http://www.edfas.org/istfa

$\checkmark$ November $13 / 1700$, 8th Conference on Frontiers of Electron Microscopy in Materials Science (National Research Instituite for Metals) Matsue, Japan. Dr. M. Takeguchi: 81-298-59-5055, www.nrim.go.jpl femm 2000

$\checkmark$ November 19/23 '00: First International Conference on Advanced Materials Processing Rotorua, New Zealand. Prof. Nigel Sammes:

n.sammes@walkato.ac.nz

$\checkmark$ December 9/13 '00: 40th Annual Meeting American Society for Cell Biology San Francisco, CA. www. ascb.org/ascb

$\checkmark$ January 20/26 '01: Multiphoton Microscopy in the Biomedical Sciences (SPIE) San Jose, CA. http://spie.org/web/meetings/calls/pw01/confs/ BO31.html

\section{In Situ Hybridization Core Lab}

An experienced individual is needed to run the in situ hybridization (ISH) research core laboratory in the Department of Pathology, Beth Israel Deaconess Medical Center, a major Harvard Medical School hospital. The laboratory services a small group of MDs and

Ph.Ds who are investigating the role of cytokines, cytokine receptors and cell signaling pathways in angiogenesis and tumor biology. This group makes extensive use of ISH and other morphological and molecular techniques. Experience with ISH and both molecular biology (design, preparation and labeling of RNA probes) and histology (tissue fixation and processing) are necessary, as well as enthusiasm for developing and using new technology. The ideal applicant will hold a Masters or Ph.D degree but individuals without such credentials will be considered if they have appropriate experience. Interested individuals should submit their $\mathrm{CV}$ and references to:

Dr. Harold F. Dvorak

Beth Israel Deaconess Medical Center

Department of Pathology, East Campus

330 Brookline Avenue

Boston, MA 02215

Beth Israel Deaconess Medical Center is an equal opportunity employer that values the strength diversity brings to the workplace. 